\title{
Larval strigeoid trematodes in anurans from southern Nigeria
}

\author{
O. EDO-TAIWO, E. OVWAH, A. A. IMASUEN, M. S. O. AISIEN* \\ Laboratory of Parasitology Research, Department of Animal and Environmental Biology, Faculty of Life Sciences, \\ University of Benin, P.M.B. 1154, Benin City, Nigeria, "E-mail: aisien@uniben.edu
}

\begin{abstract}
Summary
Anurans from locations in the rainforest, derived savannah and a monoculture plantation in Nigeria were examined for infection with strigeoid trematode larvae. Two types of metacercarial cysts were recovered. The cyst type I (rounded with fringe projections) occurred in tree frogs from the Okomu National Park, at Usen (derived savannah) and the Okomu Oil Palm Plantation (OOPP). The cyst type II was recovered from $A$. dorsalis and Ptychadena bibroni collected at OOPP. The cysts were ovoid in shape, devoid of projections at the fringes and were not subject to trypsin action. An unencysted metacercaria was found in A. dorsalis collected at Usen while mesocercaria of Alaria occurred in the lungs of Pty. pumilio at OOPP. The finding of Alaria mesocercaria in Pty. pumilio is of public health importance in view of the fact that many ranid frogs are consumed in Nigeria and other West African countries.
\end{abstract}

Keywords: anurans; strigeoid larvae; rainforest; derived savannah; Nigeria

\section{Introduction}

Adult strigeoid trematodes are intestinal parasites of aquatic reptiles, piscivorous birds and carnivorous mammals. The first intermediate hosts are snails which produce furcocercous cercariae from sporocysts (Stunkard, 1973). The metacercariae occur in snails, leeches, fish, amphibians and rarely in snakes, birds and mammals (Stunkard, 1973). In members of the genera Strigea and Alaria, an additional stage, the mesocercaria, may be interposed between the cercaria and the metacercaria and these species therefore have a four host life cycle (Stunkard, 1973). In a recent paper, Imasuen et al. (2012) reported the occurrence of an unidentified encysted strigeoid metacercariae in the body cavity of several tree frogs from a protected forest habitat in southern Nigeria. Apart from the strigeoid trematode metacercariae, the authors also reported other larval helminths, which use amphibians either as intermediate or paratenic hosts (Imasuen et al., 2012). Examination of anurans from a monoculture plantation (Oil Palm) and those collected from a derived savannah location has revealed that anurans in these locations also habour strigeiod trematode larvae. Some of the larvae recovered were encysted like those reported by Imasuen et al. (2012) while others were recovered unencysted in the body cavity and lungs, respectively.

In this paper, we report the different strigeoid trematode larvae infecting anurans collected from a monoculture plantation located in a rainforest environment and a derived savannah location in southern Nigeria.

\section{Materials and methods}

The amphibians investigated for these parasites were collected from Okomu National Park $\left(6^{\circ} 15^{\prime} \mathrm{N}\right.$ and $6^{\circ} 25^{\prime} \mathrm{N}$; $5^{\circ} 9^{\prime} \mathrm{E}$ and $\left.5^{\circ} 23^{\prime} \mathrm{E}\right)$, Okomu Oil Plantation $\left(6^{\circ} 18^{\prime} \mathrm{N}\right.$ and $6^{\circ} 26^{\prime} \mathrm{N} ; 5^{\circ} 07^{\prime}$ and $\left.5^{\circ} 25^{\prime} \mathrm{E}\right)$ and Usen $\left(6^{\circ} 45^{\prime} \mathrm{N} ; 5^{\circ} 21^{\prime} \mathrm{E}\right)$, all in Edo State of Nigeria. The amphibians were killed by immersion in Benzocaine solution, the body cavity and the lungs were examined for the presence of strigeoid trematodes. Recovered metacercariae were preserved in $70 \%$ ethanol. Specimens of the strigeoid metacercariae were incubated in $0.85 \%$ normal saline containing $0.5 \%$ trypsin at $37{ }^{\circ} \mathrm{C}$ to free the juvenile parasite. Unencysted larvae recovered from the body cavity of one tree frog were fixed (flattened and unflattened) in $5 \%$ formol-saline. A mesocercaria recovered from the lungs of one of the anurans was flattened and fixed in $5 \%$ formol-saline. Fixed specimens were transferred to specimen bottles and preserved in $5 \%$ formol-saline. Parasites were washed free of the fixative in several changes of tap water and then stained overnight in a dilute solution of acetocarmine. The specimens were dehydrated and permanent mounts made in Canada balsam. 
Table 1. Prevalence of encysted strigeoid trematode larvae in the anurans from Okomu National Park* and Okomu Oil Palm Plantation

\begin{tabular}{lcccccc}
\hline \multirow{2}{*}{ Anuran hosts } & \multicolumn{3}{c}{ Okomu National Park } & \multicolumn{3}{c}{ Okomu Oil Palm Plantation } \\
\cline { 2 - 7 } & $\begin{array}{c}\text { No. of } \\
\text { examined }\end{array}$ & Prevalence & $\begin{array}{c}\text { Mean } \\
\text { intensity }\end{array}$ & $\begin{array}{c}\text { No. of } \\
\text { examined }\end{array}$ & Prevalence & $\begin{array}{c}\text { Mean } \\
\text { intensity }\end{array}$ \\
\hline Afrixalus dorsalis & 108 & 13.8 & 3.3 & 477 & 3.2 & 25.1 \\
A. cog. nigeriensis & 25 & 4.0 & 15.0 & - & - & - \\
Chiromantis rufescens & 64 & 1.6 & 30.0 & - & - & - \\
Hyperolius fusc. burtoni & - & - & - & - & - & - \\
H. fusciventris & - & - & - & 115 & 1.7 & 81.0 \\
H. picturatus & - & - & - & 32 & 6.3 & 18.0 \\
H. sylvaticus & 25 & 4.5 & 28.0 & - & - & - \\
Hyperolius sp. & 17 & 11.7 & 10.0 & - & - & - \\
Leptopelis hyloides & 30 & 16.7 & 9.0 & - & - & - \\
Ptychadena bibroni & - & - & - & 29 & 6.9 & 32.5 \\
P. longirostris & - & - & - & 26 & - & - \\
P. mascareniensis & - & - & - & 117 & - & - \\
P. oxyrynchus & - & - & - & 29 & - & - \\
P. pumilio & - & - & - & 131 & - & - \\
\hline *Imasuen et al. (2012) & & & & & &
\end{tabular}

\section{Results}

The anurans (tree frogs) examined for strigeoid trematode larvae at the Okomu National Park as reported by Imasuen et al. (2012) are shown in Table 1. In this location, six tree frogs (Afrixalus dorsalis, Afrixalus cog. nigeriensis, Chiromantis rufescens, Hyperolius sylvaticus, Hyperolius sp. and Leptopelis hyloides) were infected. The prevalence and mean intensities in these hosts are also presented in Table 1. The metacercariae as earlier described by Imasuen et al. (2012), which we now designate as Cyst type I were rounded bodies divided into an outer hyaline layer with projections at the fringes and a dark inner core enclosing the developing larvae (Fig. 1A). The dimensions of the cyst from the Okomu National Park are shown in Table 2. The excysted juvenile from the type I cysts collected at the Okomu National Park is represented by Figure 2A. The larvae ranged from $335.5 \mu \mathrm{m}$ to $375.76 \mu \mathrm{m}(357.8 \mu \mathrm{m})$ in length. The ratio of the fore body to the hind body was 2.5:1. At the Okomu Oil Palm plantation, two types of metacer- cariae were recovered and the hosts examined are shown in Table 1. The metacerariae recovered from $H$. fusciventris (Fig. 1B) were the type I cyst recovered from tree frogs at the Okomu National Park. The metacercariae recovered from A. dorsalis and Pty. bibroni were different. These cysts were ovoid in shape (Figs. 1C and 1D) with those from A. dorsalis (Fig.1C) tapering at both ends. The inner core of the cysts from Pty. bibroni appeared thicker than those from A.dorsalis. These cysts which are designated as Cyst type II are devoid of projections at the fringes, a characteristic of the type I cysts. The dimensions of these cysts are shown in Table 2. Unlike the Cyst type I, the type II cysts were not susceptible to trypsin digestion, even at $1 \%$ concentration at $37^{\circ} \mathrm{C}$.

At the Okomu Oil Plantation, the mesocercariae of Alaria sp. occurred in the lungs of one Pty. pumilio (Fig. 2B). The mesocercaria was $429 \mu \mathrm{m}$ long and $214.72 \mu \mathrm{m}$ in breadth. The oral and ventral suckers, which were the prominent organs of this juvenile measured $120.78 \mu \mathrm{m}$ and $107.35 \mu \mathrm{m}$ in diameter, respectively.

Table 2. Dimensions of strigeoid metacercarial cyst from locations in the rainforest and derived savannah

\begin{tabular}{llcccc}
\hline Location & Cyst type & $\begin{array}{c}\text { Cyst length } \\
(\boldsymbol{\mu m})\end{array}$ & $\begin{array}{c}\text { Cyst diameter } \\
(\boldsymbol{\mu m})\end{array}$ & $\begin{array}{c}\text { Inner core length } \\
(\boldsymbol{\mu m})\end{array}$ & $\begin{array}{c}\text { Inner core diameter } \\
(\boldsymbol{\mu m})\end{array}$ \\
\hline Okomu National Park & Type I & $334(253-798)$ & $271(120-665)$ & $200(146-439)$ & $122(93-293)$ \\
Usen & Type I & $526(456-590)$ & $392(322-510)$ & $350(309-389)$ & $172(134-215)$ \\
Okomu Oil Plantation & Type I & $702(604-819)$ & $607(470-671)$ & $353(309-403)$ & $286(268-322)$ \\
Okomu Oil Plantation & Type II & & & & $416(336-523)$ \\
& A.dorsalis & $1039(832-1140)$ & $779(671-872)$ & $554(483-617)$ & $361(309-429)$ \\
\hline
\end{tabular}



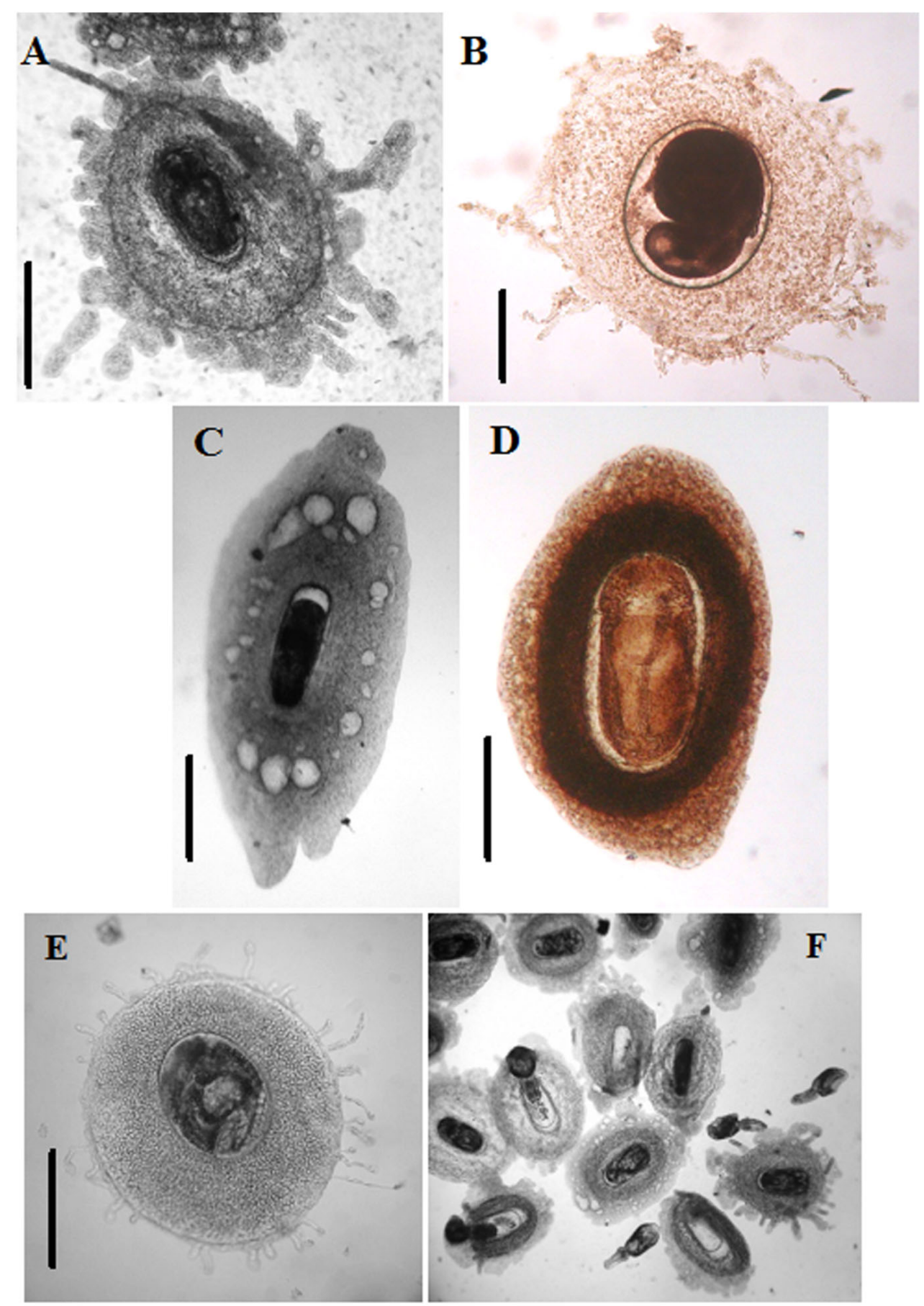

Figs. 1 A - F. Cyst types of strigeoid trematodes recovered from amphibians. A, B and E, cyst type I from tree frogs at Okomu National Park, Okomu Oil Plantation and Usen, respectively; C and D cyst type II, from A. dorsalis and Pty. bibroni, respectively at Okomu Oil Plantation; F, strigeoid trematode from cyst type I in the excystment medium. Scale bars: A $-E=200 \mu \mathrm{m}$

At Usen, which is located in the derived savannah, the encysted larval strigeoids recovered from $A$. dorsalis were the type I (Fig. 1E). The prevalence of these metacercariae in the frogs from this location was $6.9 \%$ with a mean intensity of 27.3 parasites per infected host. The dimensions of the cysts from this location are also presented in Table 2. These cysts were subject to trypsin action $(0.5 \%)$ in normal saline at $37^{\circ} \mathrm{C}$.
At Usen A. dorsalis harboured a second and unencysted metacercaria in the body cavity. Only two specimens of this metacercaria were recovered. The unflattened specimen (Fig. 2C) measured $899.14 \mu \mathrm{m}$ in length while the flattened parasite (Figure 2D) was $1076.6 \mu \mathrm{m}$ in length. The fore body to hind body ratio determined from the unflattened specimen was 10:1. 


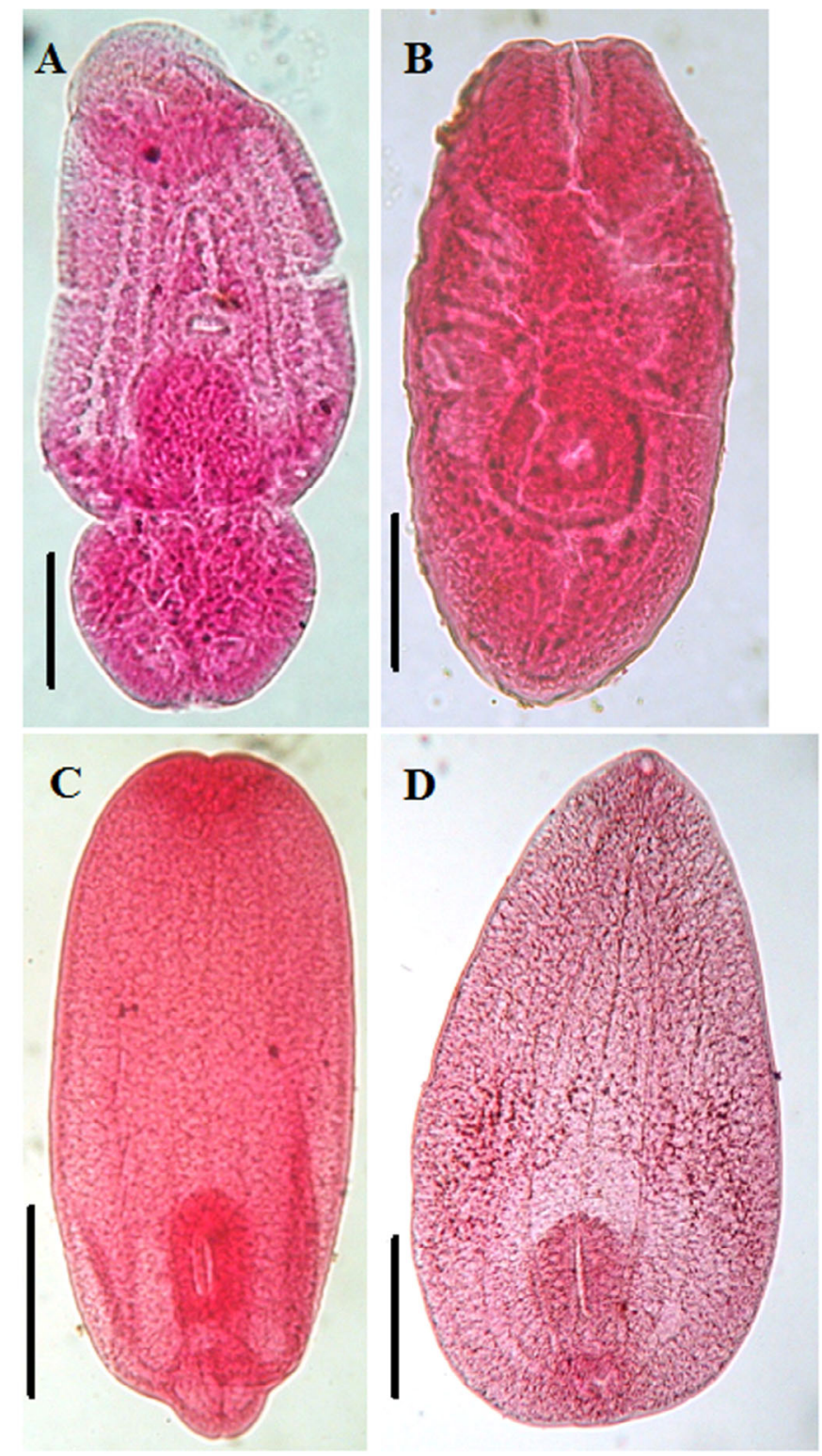

Figs. 2 A - D. Juvenile strigeoid trematodes recovered from amphibians in southern Nigeria. A, Juvenile specimen of the type 1 strigeoid (from encysted metacercaria); B, Mesocercaria of Alaria sp.; C, Unflattened specimen; D, Flattened specimen of unencyted strigeoid metacercaria. Scale bars: A: $50 \mu \mathrm{m} ; \mathrm{B}-\mathrm{D}: 250 \mu \mathrm{m}$

\section{Discussion}

Very little is known about strigeoid trematodes in Nigeria. The first report on the occurrence of this group of parasites in Nigerian anurans was a recent paper by Imasuen et al. (2012), who found encysted metacercariae of an undetermined species in a number of tree frogs at the Okomu National Park, Nigeria. These frogs were believed to serve as intermediate hosts for these parasites. Results from the present study has shown that anurans from locations in the forest (monoculture plantation) and the savannah-mosaic biotopes of southern Nigeria also serve as intermediate host to at least four types of strigeoid trematodes; two encysted forms, one unencysted form and the mesocercaria of an Alaria sp. Judging by their morphology and re- sponses to trypsin treatment, the type I metacercariae from the tree frogs of the Okomu National Park, A. dorsalis from Usen and H. fusciventris from the Okomu Oil Palm Plantation (Fig. 1 A, B and E) are most probably the same parasite, using these frogs as intermediated hosts. The definitive or paratenic hosts of these parasites are those predators that forage for prey in arboreal habitats. These may include birds and snakes, which prey on these frogs. The type II metacercariae recovered from A. dorsalis (Fig. 1C) and Pty. bibroni (Fig. 1D) collected from the Okomu Oil Palm Plantation obviously belong to another group by virtue of their morphology and the failure of trypsin to dissolve their cyst wall. Ezeyili (1998) reported that trypsin alone failed to cause the excystation of the trematode metacercariae recovered from Armadillidium vulgare. The 
juveniles were only freed when the cyst were incubated in a combination of $0.5 \%$ trypsin and $0.5 \%$ bile salts (cholic acid and deoxycholate) dissolved in Earle's balanced salt solution at $37^{\circ} \mathrm{C}$. It needs to be determined if the juveniles in these type II cysts can similarly be excysted under these conditions. It is not known if the parasites in the type II cysts which were respectively found in A. dorsalis (arboreal) and Pty. bibroni (terrestrial) both infect the same host (s). It is presumably safe to assume that the final or paratenic host of the parasites in Pty. bibroni are terrestrial in location while those in $A$. dorsalis are arboreal.

The second strigeoid metacercariae (Fig. 2C \& 2D) recovered from $A$. dorsalis at Usen belong to the Diplostomulum type (Niewiadomska, 2002), characterised by a large concave forebody and a small conical hind body. According to Niewiadomska (2002) they normally occur free, without cyst of parasite origin. Strigeoid genera known to have this metacercarial type include Diplostomum, Neodiplostomum and Alaria (Niewiadomska, 2002).

The occurrence of the Alaria mesocercaria in the anurans of the Okomu Oil Plantation is the first report of this parasite in Nigeria, albeit with a very low prevalence $(0.8 \%)$. The genus Alaria includes several species, all of which are parasitic in the small intestine of canid mammals. These mammals acquire their infection when they consume frogs harbouring mesocercariae or alternatively when they consume a paratenic host which has accumulated mesocercariae in its tissue from eating infected frogs. This study has shown that the ranid frog Ptychadena pumilio and probably other Ptychadena species harbour Alaria mesocercariae. The final fate of the mesocercaria occurring in $P$. pumilio is dependent on which of the two developmental routes known for the parasite is followed. It could develop into an adult in a canid mammal if the frog were consumed directly, thereby having a three host life cycle. Alternatively, if the frog is consumed by a snake or any other paratenic host, the final host acquires infection from this transport host; resulting in a four host life cycle. It however remains to be determined which canid mammal serves as the final host of this parasite in Nigeria.

Alaria infections in the canine host are highly pathogenic causing severe enteritis and sometimes death. The mesocercariae are also pathogenic to humans if present in large numbers. Freeman et al. (1976) reported a case of human death due to the presence of mesocercariae in almost every organ of the body. The individual is thought to have acquired the infection from eating undercooked frog legs harbouring mesocercariae. Frog meat, especially those of ranid frogs are consumed in some rural communities in Nigeria and other West African countries (Mohneke et al., 2010; Onadeko et al., 2011). Consumption of improperly cooked amphibian meat infected with a heavy mesocercariae burden could also produce such fatality. Care must therefore be taken to ensure that frog meat is properly cooked before consumption.

\section{References}

EzEYILI, C. N. (1998). Incidence, excystation and culture of metacercariae occurring in Armadillidium vulgare. B.Sc. thesis, Benin City, Nigeria: University of Benin.

Freeman, R., Stuart, P. F., Cullen, J. B., Ritchie, A. C., Mildon, A., Fernandes, B. J., Bonin, R. (1976). Fatal human infection with mesocercariae of the trematode Alaria americana. Am. J. Trop. Med. Hyg., 25: 803 - 807

Imasuen, A. A., OzEmoKA, H. J., Aisien, M. S. O. (2012). Anurans as intermediate and paratenic hosts of helminth infections in the rainforest and derived savannah biotopes of southern Nigeria. Int. J. Zool., 2012, Article ID 82370, 7 pages. DOI: 10.1155/2012/823970

MohneKe, M., OnadeKo, A. B., Hirschfeld, M., Rodel M. O. (2010). Dried or fried: amphibians in local and regional food markets in West Africa. Traffic Bulletin 22(3): $117-128$

NiEWIADOMSKA, K. (2002). The Superfamily Diplostomoidae Poirier, 1886. In: GIBSON, D. I., JONES, A., BRAY, R. I. (Eds), Keys to the Trematoda Vol. 1. London, U.K: CABI Publishing and the Natural History Museum, pp. $159-166$

Onadeko, R. I., Egomwan, R. I., Saliu, J. K. (2011). Edible amphibian species: local knowledge of their consumption in Southwest Nigeria and their nutritional value. W. Afr. J. Appl. Ecol., 19: $67-76$

STUNKARD, H. W. (1973): Studies on larvae of strigeoid trematodes from the Woods Hole, Massachusetts Region. Biol. Bull., 144: 525 - 540. DOI: 10.2307/1540306 